\title{
Retrieval of Soil Salt Content Base on High Resolution Remote Sensing Data
}

\author{
A case study in Changling, China
}

\author{
Hui Zheng ${ }^{1,2}$, Zhao-li Liu ${ }^{1, *}$ \\ 1. Northeast Institute of Geography and Agroecology Chinese Academy of Sciences, Changchun, China \\ 2. University of Chinese Academy of Sciences, Beijing, China. \\ zhenghui842@163.com
}

\begin{abstract}
Soil salinization is one of the most common land degradation processes in arid and semi-arid regions that impact the growth of many crops. Remotely sensed data has great potential for monitoring dynamic processes, including salinization. But the fluctuant microtopography controls the space distribution of soil salinity, make its have strong heterogeneous that the saline vegetation and saline soil performance the characteristics of mosaic distribution. This kind of complex and unique land surface lead to precisely retrieval of soil salt content based on remote sensing have some constraints. In this paper, we take the Changling County as the study area and through the $30 \mathrm{~cm}$ high resolution remote sensing data, which is close to the size of field sampling, photographed by airship to improve the accuracy based on remote sensing for retrieving of soil salt content. Result showed that the overall accuracy of high resolution remote sensing in retrieving soil salinity was $83.94 \%$. At the same time, the result suggests that remote sensing is a useful tool to detect soil salinity.
\end{abstract}

Keywords-soil salinizationt; soil salt content; high resolution remote sensing; field sampling

\section{INTRODUCTION}

Soil salinization is one of the most common land degradation processes in arid and semi-arid regions that is a severe environmental hazard that impacts the growth of many crops[1]. Human-induced salinization is the result of salt stored in the soil profile being mobilized by extra water provided by human activities such as irrigation [2]. Salinization problems continue to spread around the world at a rate of up to 2 million hectares a year, offsetting a good portion of the increased productivity achieved by expanding irrigation [3].There are ,in China, almost 100 million hectares saline-alkali soil. To combat soil salinization, different technical measures and strategies have been developed in the past century. However, soil salinity is quite time- and space-dynamic since salinization is the consequence of different complex processes of salt redistribution that depend on natural conditions, system features, agricultural practices and drainage management. Therefore, it is necessary to study of salinity from large-scale and multi-temporal.

By providing fast, timely, relatively cheap, and repetitive data, remote sensing plays an important role in detecting, mapping, and monitoring salt-affected surface features [4]. Large numbers of studies have proven that remote sensing is a useful and promising method to identify salt-affected soils and retrieve soil salt content [5-13].In these studies, however, they used the resolution of remote sensing considerably larger than the field sampling size and soil salt content changes very rapidly in the saline-alkali land; these reasons lead to low accuracy based on remote sensing for retrieving of soil salt content. Therefore, this paper use the $30 \mathrm{~cm}$ high resolution remote sensing data, which is close to the field sampling size that the size of quadrat is about $10 \mathrm{~cm} \times 10 \mathrm{~cm}$, photographed by airship to improve the accuracy based on remote sensing for retrieving of soil salt content.

\section{MATERIALS AND METHODS}

\section{A. Study Area, Imagery Acquisition and Field Sampling} Collection

The study area was selected in the Changling County, locates in western Jilin province of Northeast China (Fig.1).

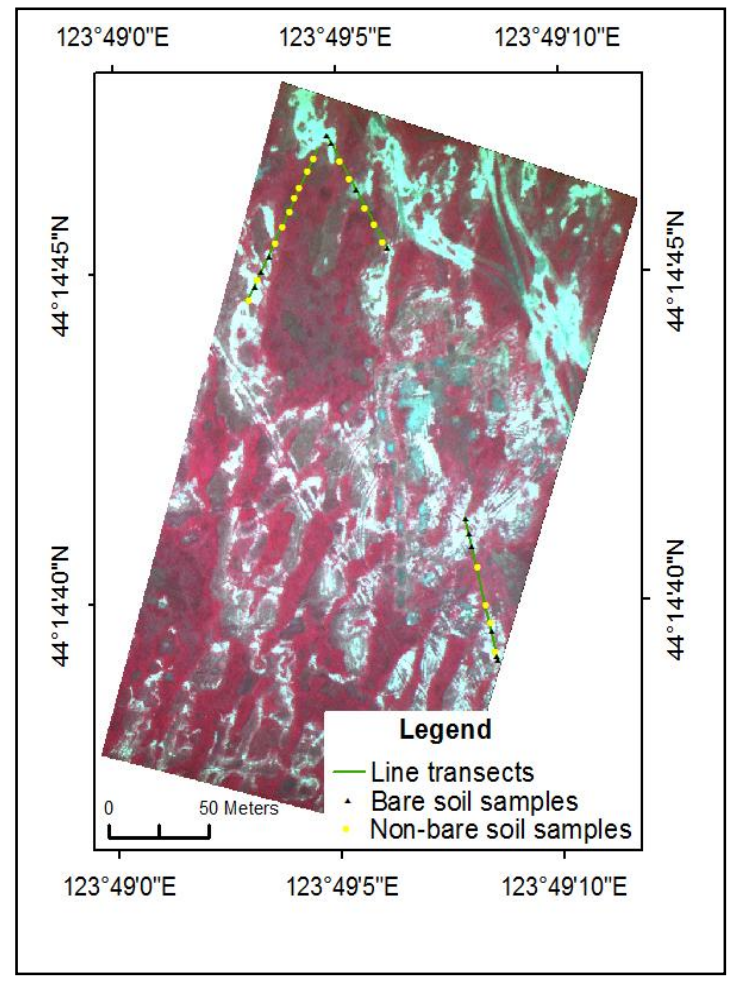

Figure1. Image of the study area, acquired at $300 \mathrm{~m}$, shown in false color composite.

Supported by the National High Technology Research and Development Program (863 Program), NO.2009AA12Z136 
The annual average air temperature is $4.9^{\circ} \mathrm{C}$, with monthly averages ranging from $-15.5^{\circ} \mathrm{C}$ in January to $23.5^{\circ} \mathrm{C}$ in July. Annual rainfall is about $470 \mathrm{~mm}$ on average, $86 \%$ of which falls during the May to September. Soil salinity has always been a threat to the sustainable development of the area.

The airborne sensor, MS4100 high-resolution 3-CCD camera, produces images (1080 row x 1920 column pixels) in three bands: Green (0.55-0.59um), Red (0.67-0.71um) and near infrared (NIR;0.80-0.86um). Imagery was acquired under clear sky conditions around 10:00 AM CCT on 13 August 2010. The images were collected at altitudes of about $300 \mathrm{~m}$ AGL (Above Ground Level), resulting in nominal spatial resolution of 0.30 $\mathrm{m}$.

Field investigation and sampling were collected as the same day as the image data acquisition to evaluate the accuracy of salinity detection using remote sensing. Then a total of 31 soil samples along three line transects, all the size of samples are $10 \mathrm{~cm}$ long, $10 \mathrm{~cm}$ wide and $5 \mathrm{~cm}$ deep, were collected from the surface soil layer and located using the differential GPS (DGPS) as shown in fig.1. There are 18 bare soil samples and 13 nonbare soil samples (or vegetation covered samples). All the samples were measured soil salt content in laboratory.

\section{B. Data Preprocessing and Image Classification}

Prior to analysis, the image was registered to the appropriate digital orthophoto quarter quadrangle (DOQQ). The registration process used the nearest neighbor resampling and the root mean square error (RMSE) was not greater than $0.10 \mathrm{~m}$. Gauss-Kruger projection Zone 41, Spheroid WGS 84 and datum xi'an 80 were used as the projection parameters.

The image acquired was firstly converted into Normalized Difference Vegetation Index (NDVI) images using the band ratioing technique; the NDVI was calculated for the image data as (NIR - Red) / (NIR + Red). For the study area was classified into two categories: bare soil $(\mathrm{NDVI}<0.1)$ and non-bare soil $(\mathrm{NDVI}>=0.1)$ that is vegetation covered area.

\section{Construction Statistics Model}

Salt-affected soil, in general, showed relatively higher spectral response in the visible and near-infrared regions of the spectrum as compared to normal cultivated soils. Further, strongly saline-sodic soils were found to have higher spectral response as compared to moderately saline-sodic soils. Therefore the relationship between Digital Number (DN) values of remote sensing and soil salinity on different soil surface conditions can be established. But the vegetation cover causes spectral confusions and modifies the overall spectral response pattern of salt-affected soils especially in the green and red spectral bands [5, 14]. In this paper, the high resolution remote sensing data based NDVI was taken to separate bare soil and vegetation cover. So that the statistics model for salt content of bare soil and the DN values of remote sensing was constructed. We used 9 bare soil samples for constructing the statistics model and the other used for accuracy assessment. Through analyzing three bands (Green, Red, NIR) of remote sensing data, finding the DN values of red band has the highest correlation $\left(\mathrm{R}^{2}=0.73537\right)$ with the salt content of bare soil (Fig.2). The statistics model as follow:

$$
\alpha=0.03 * \chi+3.35
$$

$\alpha$ represents the soil salt content, $\chi$ represents the DN values of remote sensing.

The predominant mechanism causing the accumulation of salt in arid and semi-arid regions is loss of water through evapotranspiration, leaving ever-increasing concentrations of salts in the remaining water. Effects of soil salinity are manifested in loss of stand, reduced plant growth. Salinity limits water uptake by plants by reducing the osmotic potential making it more difficult for the plant to extract water. Salinity may also cause specific-ion toxicity or upset the nutritional balance of plants. So the soil salt content was strong correlation relatively with vegetation growth. The NDVI as indicator of vegetation growth was used to construct the statistics model for salt content of non-bare soil. We used 12 non-bare soil samples for constructing the statistics model and the other used for accuracy assessment. The relationship between NDVI and the salt content of non-bare soil show in Fig.3. The statistics model as follow:

$$
\theta=(-4.03) * \beta+2.99
$$

$\theta$ represents the soil salt content, $\beta$ represents the NDVI values of remote sensing.

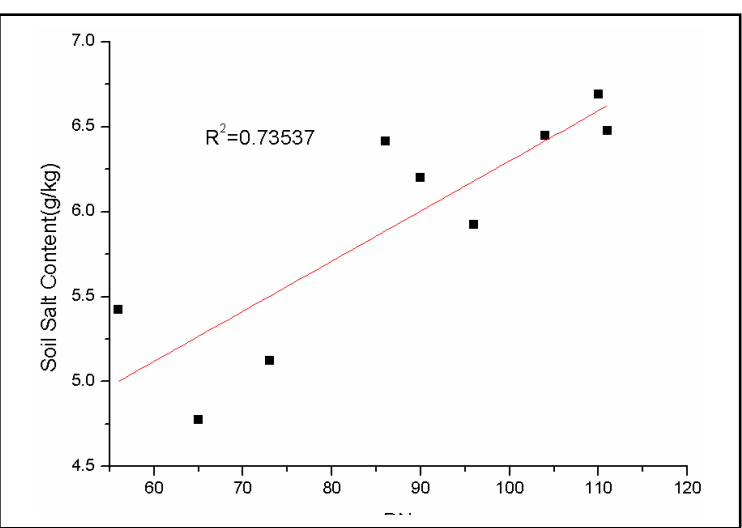

Figure2. The relationship between DN values of red band and salt content of bare soil.

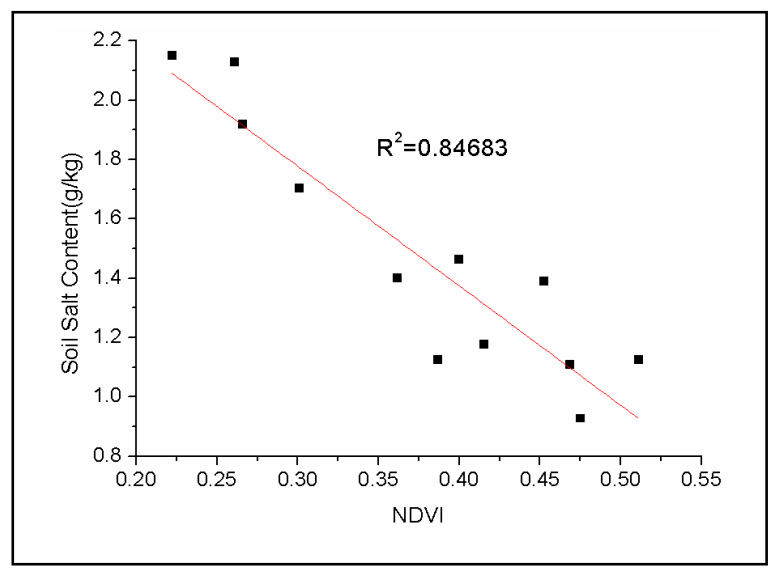

Figure3. The relationship between NDVI values of remote sensing and salt content of non-bare soil. 


\section{RESUlTS AND ANALYSES}

\section{A. Soil Salt Content maps}

Following the above method, we get the soil salt content of bare soil map (Fig.4) and the soil salt content of bare soil nonbare soil map (Fig.5). Fig.6 show the study area soil salt content through combined the soil salt content of bare soil and the soil salt content of non-bare soil.

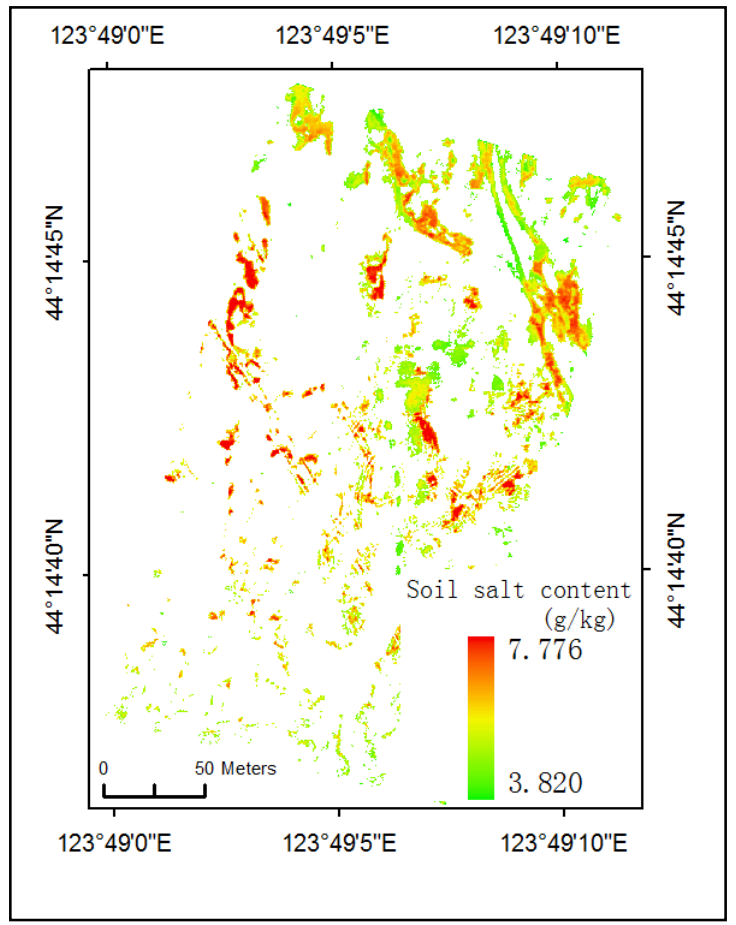

Figure4. The soil salt content of bare soil of study area

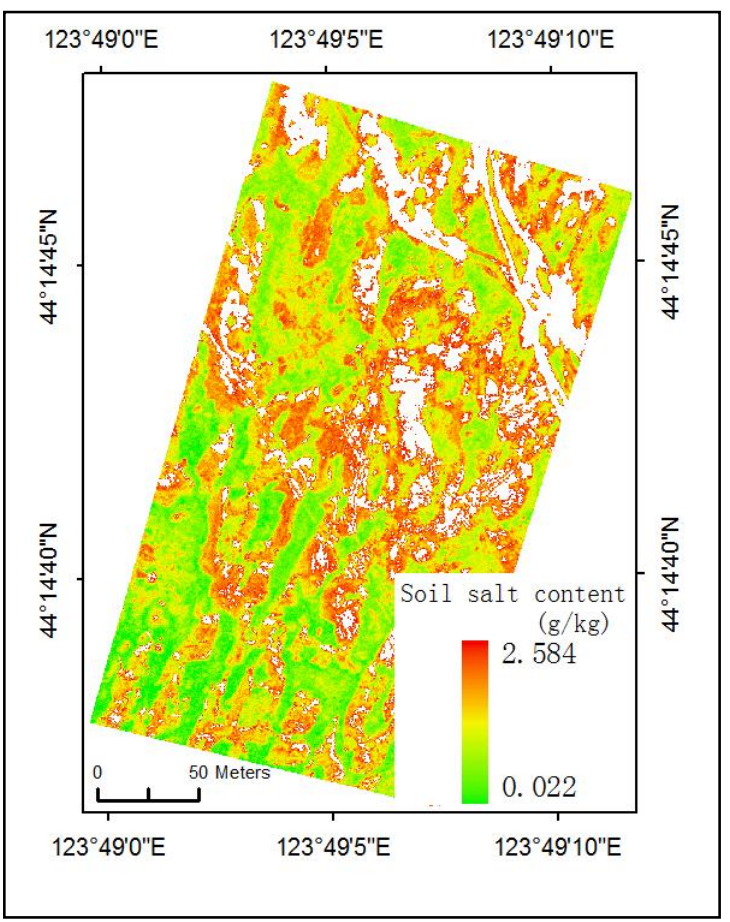

Figure5. The soil salt content of non-bare soil of study area

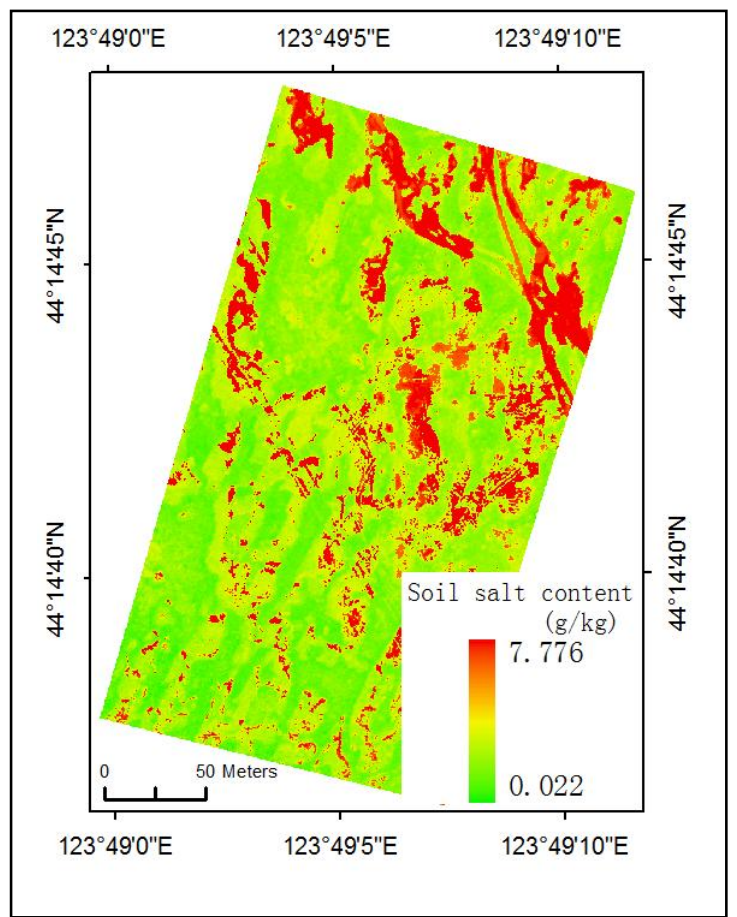

Figure6. The soil salt content of study area

From Fig.4 and Fig.5, the soil salt content of bare soil area has a significantly higher than the soil salt content of non-bare soil area. For the soil salt content of the non-bare soil area which is close to bare soil area higher than the area which is far away bare soil area. For the bare soil, however, this situation is reverse. From Fig.6, however, the soil salt content has a sharply changed at the edges of bare soil area which is close to non-bare soil area, vice versa. This condition, maybe because we regard as the two objects (bare soil and non-bare soil) are independent when we constructed the two statistics models. In nature, in fact, they are dependency.

\section{B. Accuracy Assessment}

In this study, there have 4 bare soil samples and 6 non-bare soil samples for accuracy assessment. The accuracy assessment of bare soil area and non-bare soil area were computed (shown in Table I and Table II ). From the two tables, we can see the accuracy of the soil salt content of non-bare soil area which retrieved by NDVI is higher than the soil salt content of nonbare soil area which retrieved by DN.

TABLE I. ACCURACY ASSESSMENT OF BARE SOIL

\begin{tabular}{|c|c|c|c|}
\hline \multirow{2}{*}{$\begin{array}{c}\text { Field } \\
\text { Samples }\end{array}$} & $\begin{array}{c}|c| \\
\text { Measured values } \\
(\mathbf{g} / \mathbf{k g})\end{array}$ & $\begin{array}{c}\text { Predicted values } \\
(\mathbf{g} / \mathbf{k g})\end{array}$ & $\begin{array}{c}\text { Accuracy } \\
(\boldsymbol{\%})\end{array}$ \\
\hline 1 & 7.707 & 5.849 & 75.90 \\
\hline 2 & 7.237 & 5.472 & 75.61 \\
\hline 3 & 6.642 & 5.085 & 76.56 \\
\hline 4 & 5.842 & 4.721 & 80.81 \\
\hline Mean & 6.857 & 5.282 & 77.22 \\
\hline
\end{tabular}


TABLE II. ACCURACY ASSESSMENT OF NON-BARE SOIL

\begin{tabular}{|c|l|c|c|}
\hline \multirow{2}{*}{$\begin{array}{c}\text { Field } \\
\text { Samples }\end{array}$} & $\begin{array}{c}\text { Measured values } \\
(\mathbf{g} / \mathbf{k g})\end{array}$ & $\begin{array}{c}\text { Predicted values } \\
(\mathbf{g} / \mathbf{k g})\end{array}$ & $\begin{array}{c}\text { Accuracy } \\
(\%)\end{array}$ \\
\hline 1 & 2.172 & 1.859 & 85.61 \\
\hline 2 & 1.401 & 1.244 & 88.80 \\
\hline 3 & 1.707 & 1.531 & 89.67 \\
\hline 4 & 2.273 & 2.081 & 91.53 \\
\hline 5 & 1.488 & 1.332 & 89.53 \\
\hline 6 & 1.848 & 1.579 & 85.43 \\
\hline Mean & 1.815 & 1.604 & 88.43 \\
\hline
\end{tabular}

The mean accuracy of the bare soil area and the non-bare soil area is $77.22 \%$ and $88.43 \%$, respectively. Through the two tables, the overall accuracy that is $83.94 \%$ was computed. The accuracy of retrieval based on high resolution remote sensing data, which is close to the field sampling size, has obviously improved compare to that used coarse resolution remote sensing data.

But the result of accuracy is still low may because that (1) quantity and mineralogy of salts, together with soil moisture, colour, and roughness, are the main factors affecting salt reflectance, and (2) the terrain surface can be directly affecting salt reflectance or indirectly affecting vegetation type and growth, and (3) in salt-affected areas, spectral confusions between different surface features are common. For example, a white saline crust and a shiny silty crust have both similar high reflectance values. This hampers the spectral separability of salt-affected areas. In this study, however, we were just classified into one category for all bare soil area.

\section{CONCLUSIONS}

By providing fast, timely, relatively cheap, and repetitive data, remote sensing plays an important role for retrieving and mapping soil salt content of salt-affected area. The accuracy of the bare soil area, the non-bare soil area and the overall accuracy is $77.22 \%, 88.43 \%, 83.94 \%$, respectively. The accuracy of retrieval based on high resolution remote sensing data, which is close to the field sampling size, has obviously improved compare to that used coarse resolution remote sensing data.

But the result of accuracy is still low may because that surface reflectance is full of ambiguity, and some soil surface conditions such as gravely surface, soil mineralogy, organic matter, soil moisture, particle size distribution, soil structure and crusted surface may hinder the reflectance of soils. The best method for improving result of accuracy base on remote sensing that is integrated remote sensing data with GIS data, soil surface condition data, field samples data and laboratory data.

\section{REFERENCES}

[1] D. Hillel, "Salinity management for sustainable irrigation: integrating science, environment, and economics." The World Bank: Washington D.C., 2000.

[2] I. Szabolcs, "Salt-Affected Soils," CRC Press, Boca Raton, FL., 1989.

[3] S. Postel, "Pillar of Sand: Can the Irrigation Miracle Last," W.W. Norton and Co., New York, 1999.

[4] G. I. Metternicht, and J. A. Zinck, "Remote sensing of soil salinity: potentials and constraints," Remote Sens. Environ., vol. 85, pp. 1-20, April 2003.

[5] B. R. M. Rao, R. C. Sharma, S. N. Das, T. R. Sankar, R. S. Dwivedi, el at. "Spectral behaviour of salt-affecled soils," INT. J. Remote Sens. , vol. 16, pp. 125- 2136, April 1955.

[6] D. Wang, C. Wilson, and M. C. Shannon, "Interpretation of salinity and irrigation effects on soybean canopy reflectance in visible and near-infrared spectrum domain," INT. J. Remote Sens. , vol. 23, pp., 811- 824. , March 2002.

[7] R. L.Dehaan, and G.R.Taylor, "Field-derived spectra of salinized soils and vegetation as indicators of irrigation-induced soil salinization," Remote Sens. Environ., vol. 80, pp.406417,June 2002.

[8] B. Mougenot, G. F. Epema, and M. Pouget, "Remote sensing of salt affected soils," Remote Sens. Environ., vol. 7, pp, 241-259, 1993.

[9] J. W. Wu, B. Vincent, J. Z. Yang, S. Bouarfa, and A.Vidal, "Remote Sensing Monitoring of Changes in Soil Salinity: A Case Study in Inner Mongolia, China," Sensor, vol. 8,pp.70357049, November 2008

[10] Q. H. Fu, S. X. Ni, S.X. Wang, and Y. Zhu, "Retrieval of soil salt content based on remote sensing," Transactions of the CSAE, vol. 23, pp.48-54,2007

[11] D.L. Corwin, and S.M. Lesch, "Apparent soil electrical conductivity measurements in agriculture," Computers and Electronics in Agriculture, vol.46, pp. 11-43, 2005.

[12] R. Dehaan, and G.R. Taylor, "Image-derived spectral endmembers as indicators of salinisation," INT. J. Remote Sens. vol. 24, pp.775-794, 2003

[13] A. Eldiery, L. A. Garcia, and R. M. Reich, "Estimating Soil Salinity from Remote Sensing Data in Corn Fields," Hydrology Days, pp. 31-41, 2005.

[14] Y. Z. Wu, Q. J. Tian, J. F. Ji, J. Chen, and F. M. Hui, "Soil Remote Sensing Research Theory Method and Application," Remote Sensing Information, pp.40-47, 2003. 